\title{
Notes on the ecology of Armillariella mellea in Finland
}

\author{
Veikko Hintikka
}

Finnish Forest Research Institute, Unioninkatu 40 A, SF-00170 Helsinki 17, Finland

Abstract. The infection biology of Armillariella mellea in young pine seedlings is described. Evidence supports the view that the bending of seedlings by snow in winter may be one of the main primary causes for the infection of root systems by rhizomorphs. In spruces, infection may take place from the soils by rhizomorphs, as well as from air by spores, or from stumps via root grafts. The external appearance of spruces suffering from heart rot is discussed.

Rhizomorphs occur very abundantly in forest soils in South Finland, and based on their ability to regenerate after cutting, as well as on their ability to grow under laboratory conditions, the majority of those found in the soil seem to be living and capable of producing new rhizomorphs.

During the summer, freshly cut pieces of unbarked wood were colonized very rapidly in forest humus by rhizomorphs of Armillariella. The sheath-like rhizomorphs grew as fast as $5 \mathrm{~mm}$ a day in the phloem. Spruce phloem was infected most easily, pine, larch and birch wood quite easily, Populus, Salix, Sorbus, and Alnus wood more slowly, and wood of Juniperus not at all. When fresh unbarked wood was infected in the laboratory, a similar variation in resistance between tree species was obtained.

The influence of temperature, terpenes and cyanogenic glycosides as well as carbon dioxide, on the resistance of different tree species is discussed.

The results are discussed in relation to the conditions existing in forest soils, and the independence of growing rhizomorph tips on oxygen and nutrients may have importance. in the colonization of cambium and wood in waterlogged soils.

\section{Introduction}

The biology of the almost cosmopolitan tree parasite Armillariella mellea (Vahl) Karst. (Armillaria mellea (Vahl ex Fr.) Kumm.) has received considerable attention since its pathogenity was first detected in the year 1873 by the famous German forest pathologist Robert Hartig (DAY 1927, Thomas 1934, Leagh 1939, Sokolov 1964, 1970, Rishbeth 1964, 1971, Zyaha 1970). In Nordic countries, the species is known to be a harmful parasite of forest trees (Molin \& RenNerfelt 1958, Yde-ANDERSEN 1959; BJörkMAN et. al. 1964; Roll-Hansen 1970; Elfving 1905, Liro 1924, Kangas 1937, 1952). According to Kangas (1937), in certain areas it is harmful for the regeneration of pine and it is commonly found in drying spruces (Kangas 1946, JuUtinen
1955). As a causal agent in the heart rot of spruces, it is also of considerable importance (Kangas 1952, Kallio \& Norokorpi 1972).

The author has made observations on the biology of Armillariella mellea in Finland during the years 1968-1972, and some preliminary results are presented in this paper. The main problems have been the questions about infection paths in tree roots and the entry of the fungus into the roots, and the resistance of different tree species to infection, on which questions some related investigations have already been carried out (HINTIKKA 1972).

The species is known to be variable both in regard to the appearance of basidiocarps (Romagnesi 1973) as well asaseptic cultures (RAABE 1967). Evidently, the genetics of $\mathrm{Ar}$ millariella seems to suggest that it is an aberrant type among agarics (RAPER 1966, 
Hintikka 1973). Especially late in the season, darker forms commonly occur (see TuomIKoskI 1955), but the species is treated here collectively as one taxon, as the main emphasis was laid on the vegetative phase of the life cycle. The main part of the investigation was carried out at the Ruotsinkylä Experimental Forest ca. $25 \mathrm{~km}$ north of Helsinki.

\section{Occurrence of Armillariella mellea in Finland}

Armillariella mellea occurs abundantly in South and Central Finland, basidiocarps being visible on and around rotten stumps or logs, or on standing dead trees. Its frequency seems to become somewhat lower in north Finland, although the species is still met with sub-alpine birch forests (Kallio \& KanKaINEN 1964). In south Finland, the basidiocarps of this species were very rare in 1968, occurring mainly in spruce swamps in the second half August, and completely lacking later in the fall, although in normal years it is an extremely common colonizer of rotten wood from late August to late October. In fact, it forms an important ingredient of the edible mushroom crop of Finland.

Armillariella occurs most commonly as a parasite of pine seedlings and as a causal agent in the heart rot of spruce, and in these cases the damage is also economically important. As a parasite, it is often also found in birches, where the basidiocarps often emerge from under the surface of the roots, and the rhizomorphs occasionally colonize the cambium up to as high as $2-3 \mathrm{~m}$ in. dying trees. In Populus tremula, it occurs in addition to heart rot in larger trees (see also EKLUND and WenNMARK 1925, BJörkman et al. 1964) also in the root suckers, the base of which are often infected by Armillariella, and evidently for this reason are sometimes killed.

As a saprophyte, Armillariella seems to prefer the wood of deciduous trees to some extent, especially stumps of birch, but it also occurs commonly on spruce, although more rarely on pine stumps. On wood of Sorbus aucuparia and Populus tremula as well as Alnus species, it is only usually met with in an advanced stage of decay, and it is found also on Quercus, Salix fragilis, Fraxinus, and Tilia wood.

Armillariella is most common in more productive and fresher biotopes, and late in the season is found on mull soils where it originates from rhizomorphs. It also occurs in dry pine forests, but seems to be largely absent from forested Sphagnum swamps, except in places with a thin peat layer and where the ground water is moving.

\section{Occurrence of Armillariella as a parasite of Pinus silvestris}

The symptoms in diseased pine trees infected by Armillariella have been described in Finnish conditions by KANGAS (1937), with which observations the present investigation in general agrees.

Damage caused by Armillariella was found in pine regeneration areas at the following localities: Ab: Bromarv (1), Lohja (2). N: Tammisaari (1), Hyvinkää (3), Nurmijärvi (3), Inkoo (1), Tuusula (2), Mäntsälä (1). St: Köyliö (1), Jämijärvi (1), Hämeenkyrö (1). Ta: Hausjärvi (4), Kärkölä (1). Sa: Savitaipale (5), Imatra (1). Ob: Rovaniemi (1). The number in parentheses indicates the number of stands. Isolated pine seedlings killed by this fungus were seen in several additional localities.

Most of the regeneration areas were planted, and the seedlings attacked were $1 / 2-11 / 2$ metres high, and an age of around 10-15 years. Several seeded areas were also found to have diseased seedlings, and it was characteristic that Armillariella killed only a few plant in a spot seeded clump, the remaining ones being vigorous, and often with no sign of infection. The fungus attacked a few naturally regenerated areas too. The largest plant killed by this fungus was $21 / 2$ metres high.

In the years 1968-1970, about 200 pine seedlings, both infected as well as non-infected, were marked with numbered aluminium plates in different parts of South Finland, and the course of the infection symptoms was recorded throughout successive years.

As a rule, the growth of seedlings suddenly stops, usually during the growing season, or at the end of it, and the needles turn slightly greyish or yellowish, compared with healthy seedlings. No signs of growth retardation can be seen in previous years (Fig. 1), and the shoot elongation of the previous year is perfectly normal, although the fungus has already been about one year in the root system 
of the plant. At the time when the needles turn yellowish or greyish, the root system is totally dead, and the cambial zone of the stem base is filled with plate-like rhizomorphs. In the following summer, the needles turn brown and fall during the next winter and basidiocarps appear in the autumn. The wellknown vigorous resin excudation at the root base is very characteristic, and often causes considerable thickening at the root base. As a rule, the rhizomorphs can be seen at the root base or attached to the roots.

The mycelium and rhizomorphs of $\mathrm{Ar}$ millariella do not usually rise $20-25 \mathrm{~cm}$ above the root base, and above this point, isolations yield only molds or other fungi. The

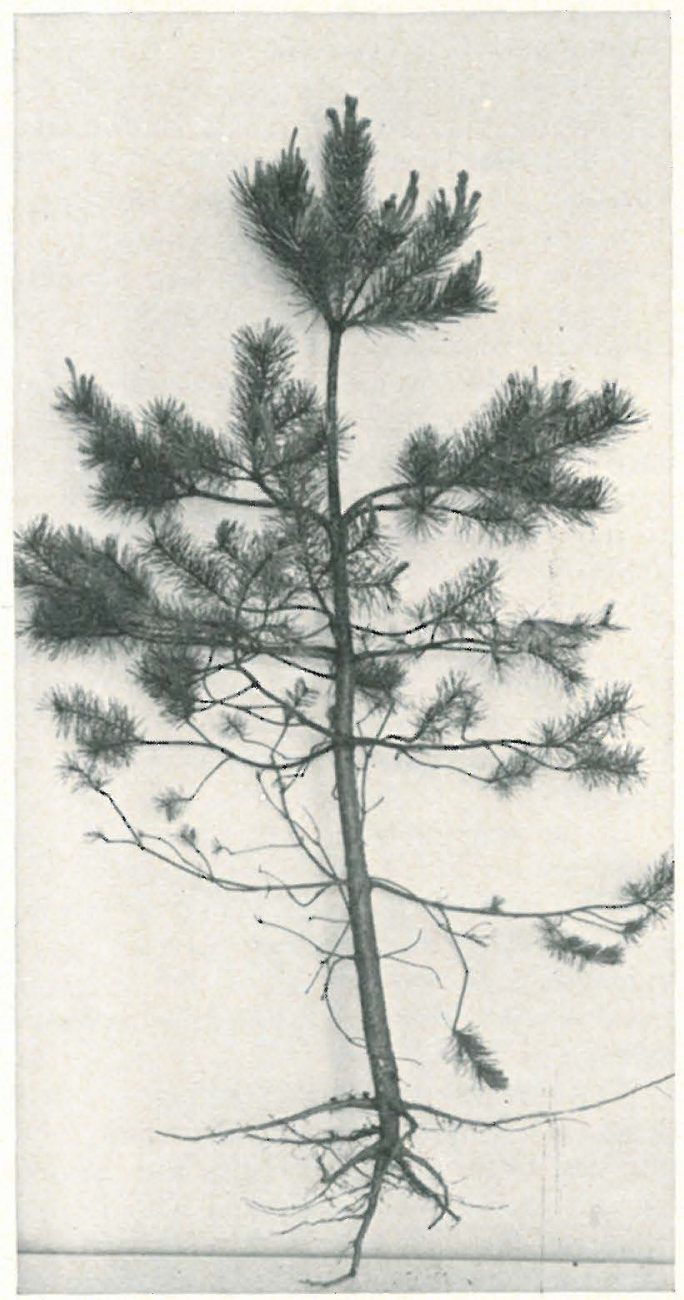

Fig. 1. Pine sapling, killed by Armillariella. Note vigorous growth in preceding years. Tammisaari, Skogby. July 1969. mycelium of Armillariella does not seem to spread very much after the death of the plant, and is restricted in general to the root system. Above the root base, larvae of Pissodes-beetles appear, which by partly consuming the cambium also hinder the upwards spread of Armillariella.

Observations on the course of infection in pine seedlings. The diseased seedlings usually showed such intensive resin accumulation in the root system, that the place of initial penetration was impossible to trace. In general, the fungus seemed to attack the root collar, remain there for a few years, and in thinner roots the fan-like mycelium usually spread outwards. Possible injuries were difficult to trace due to the thick layers of resin, which partly damaged the bark layer.

In all attacked stands, stumps of deciduous trees (birch) as well as pine and spruce were left from logging operations, and were usually about 10-15 years old. In the sand and humus around these stumps, the rhizomorphs of Armillariella were found, as well as around the roots of infected seedlings, thus suggesting that infection by rhizomorphs takes place from the soil (Hartig 1873, Greig 1962, ZYGHA 1970).

On the basis of these observations, the following possible infection course seems at present to be probable. At several damaged stands, especially in the parishes of Hyvinkää and Hausjärvi, the saplings were heavily bent by snow during the winter. For example in the stand depicted in Fig. 2, most of the trees were bent to the ground, and consequently the root bases were very strongly strained. A number of the bent trees was able to straighten up (see also Oliver 1970), but the root system remained much more loosely attached to the soil than in unbent seedlings (see Hintikka 1972). In these seedlings, injuries or broken roots very commonly occurred at the point where the bending was greatest (Fig. 3), which evidently could not be attributed to causes other than snow or other mechanical bending. This view is also supported by the presence of reaction wood in the upper parts of the stem, usually $2-3$ years before death caused by Armillariella, which thus indicated some mechanical bending force.

Insect injuries were fairly common in the young pine seedlings investigated, but at 

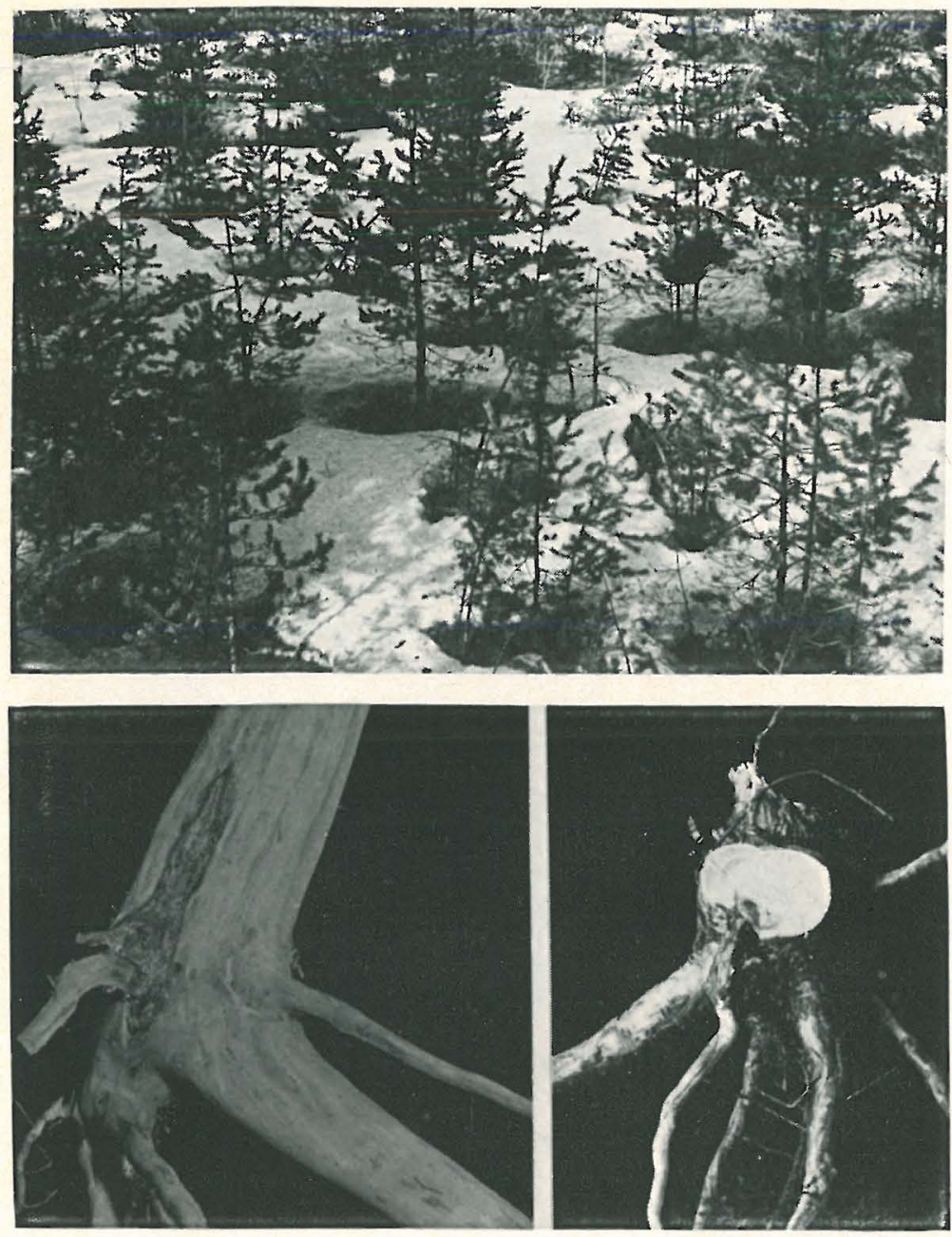

Fig. 2. Snow damage in an about 15 year old pine regeneration area in Hausjärvi, Erkylä. About half of the bent saplings were colonized by Armillariella by 1972 . April 23, 1969.

Fig. 3. Healing injuries in pine saplings, the main cause of which evidently is the snow pressure in winter. No fungi were isolated from the injured wood. Erkylä, spring 1971. present they do not seem to be main primary entry points for Armillariella. The insect injuries (caused by beetles) are often concentrated in certain roots, which, judging by the situation of pressure wood in the stem, have been exposed to bending forces in the inclination of the stem.

In this connection, it should be mentioned that Armillariella was found to occur on several occasions in Ruotsinkylä Experimental Forest as a parasite in undergrowth aspen suckers. The infection by rhizomorphs evidently took place in the humus layer at places where the bending of the stem is greatest, i.e. when snow accumulates on the branches.

It seems probable that the initial cause for penetration in pine seedlings is the weight of the snow in winter, which causes injuries at the root base, and by diminishing the vigour the penetration of rhizomorphs into the roots is allowed.

The susceptibility of trees to infection by Armillariella has sometimes been attributed to the differencies in the development of the root systems. According to RitTer and PöNTör (1969) the development of root systems is critical for infection, and CHIBA and Ogawa (1965) attribute the different susceptibility of Larix-species to infection to different rooting depths.

\section{Notes on the external symptoms of infection of Armillariella in spruces}

As pointed out by Molin \& Rennerfelt (1959) and Sokolov (1964, p. 76), spruces colonized by Armillariella have a definitely characteristic external appearance. Because 


\section{Infection experiments in living trees}

Method. Armillariella strains isolated from pine, spruce and birch wood were cultivated aseptically on autoclaved spruce bark pieces or pine wood chips in distilled water, on which a fairly good growth was obtained. After $11 / 2-2$ months, pieces were placed into wounds made by a knife on the root bark of corresponding trees, forced deeply between the bark and the wood, and then the bark was pressed back to its original position. The wound remained uncovered or was covered with paraffin wax. In addition, $\varnothing 5 \mathrm{~mm}$ holes were drilled into the heart wood of birch, inoculum was placed into them, and then closed with rubber stoppers. Attempts were made to infect the following trees: pine seedlings, $0.5-3 \mathrm{~m}$ high, spruce and birch roots, the basal bark of Sorbus aucuparia and Salix caprea, and the heart wood of Betula verrucosa. In conifers, the inoculation as a rule produced great amounts of resin, which covered the wound and evidently killed the inoculum. In Betula, decay was initiated from the hole, but Armillariella could not be isolated after 6 months. In addition, living rhizomorphs were taken from nature and placed under the bark of pines, but with similar negative results.

In view of the easy infection of recently cut spruce wood, the results seem to indicate that the excretion of resin is one of the chief methods of resistance. Armillariella is rather sensitive to the action of volatile compounds, which are found in the resin (see p.) and it is possible that in cut wood, the production of resin is weakened allowing Armillariella subcortical rhizomorphs to penetrate into the phloem.

Although the isolates of Armillariella are known to differ widely in regard to their pathogenicity (RAABE 1967, 1972, AzEvedo 1971), an additional reason for the absence of infection seems to be in the amount of inoculum potential, which according to GarRetT (1956) seems to be critical for the infection by rhizomorphs, as in each case the inoculum was smaller than in natural infections.

\section{Biology of rhizomorphs in forest soils}

As the observations reported above, as well as the literature (e.g. Sokolov 1964, MoR-

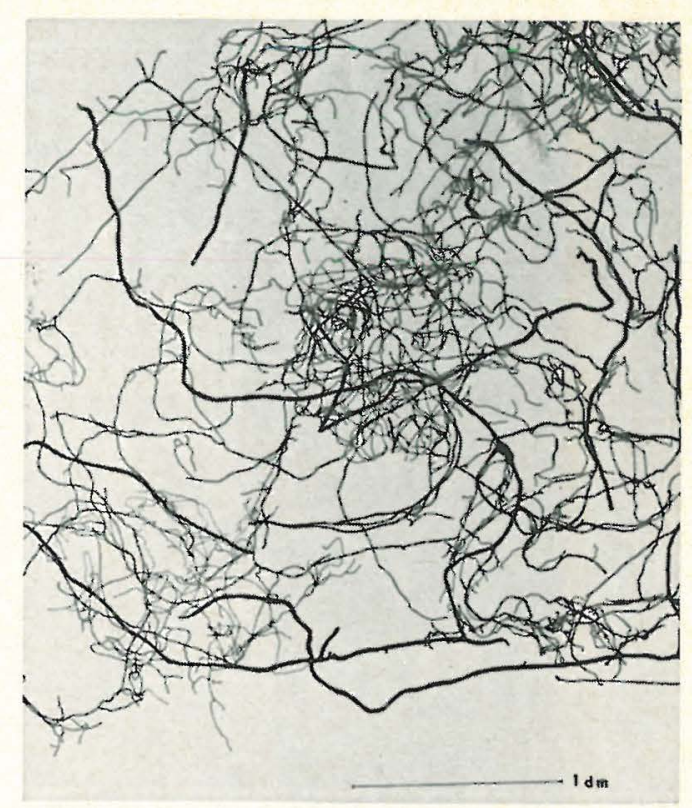

Fig. 7. Total amount of rhizomorphs in a humus sample $(20 \times 20 \times 10 \mathrm{~cm})$ from a 70 -year old spruce stand of Myrtillus type on sandy soil. Rhizomorphs approximately in natural position.

QUER et al. 1967, Swift 1972), indicated that infection by rhizomorphs in the soil forms an important, if not exclusive means of entry into the tree roots, a survey was made on the occurrence, viability, and colonization of wood by rhizomorphs. In regard to Nordic conditions, this problem has received only little attentation. However, during the investigation diseased spruces were found in which the infection evidently had taken place from the air or via root grafts.

In the preliminary observations, it turned out that rhizomorphs of Armillariella occur very abundantly in forest humus layers. For instance, in a 70 year old spruce forest on OMT type, the amount of rhizomorphs (Fig. 7) clearly exceeded that of rhizomes of higher plants. The identification of the rhizomorphs of Armillariella is not always possible in the field, as certain rhizomes (especially those of Lastrea dryopteris) are very similar; however, under the microscope, the rhizomorphs can be easily distinguished by their floccose hyphal nature.

Table 1 indicates some determinations of the amount of Armillariella rhizomorphs in forest humus. From each stand 5-10 samples of about $15 \times 15 \mathrm{~cm}$ of the humus layer were 
Table 1. Examples of the amount of rhizomorphs of Armillariella in different forest site types in South Finland expressed as $\mathrm{cm}$ rhizomorphs per $\mathrm{dm}^{2}$ of $\mathrm{h}$.mus layer.

Vaccinium type

Tuusula, Ruotsinkylä Experimental Forest 150 year old pine stand, no stumps

$\longrightarrow-20$ year old pine stand, with pine stumps

$\longrightarrow$ - 45 year old stand of Pinus murrayana, stumps abundant

Tuusula, Ruskela 15 year old pine plantation, with damage by Armillariella, birch stumps present

Tammisaari, natural regeneration area with damage by $A r$ millariella, pine stumps

Lapinjärvi Experimental Forest, pine stand

Hausjärvi, Peurapää, pine regeneration area

Hausjärvi, Erkylä, as preceding

Hausjärvi, Hikiä, as preceding

$\longrightarrow-\gg-$, as preceding

Myrtillus type

Tuusula, Ruotsinkylä Experimental Forest

$\longrightarrow-15$ year old pine plantation

$\longrightarrow-80$ year old spruce stand

$\longrightarrow$ - spruce-birch stand, unlogged for 45 years

$\longrightarrow-25$ years old spruce stand

$\longrightarrow$ - ca. 50 year old pine stand

$\longrightarrow-60-70$ year old spruce stand with birch stumps

$\longrightarrow$ - preceding

$\longrightarrow$ - ca. 50 years old spruce stand on till soil

Lapinjärvi Experimental Forest, young mixed forest

- - mixed forest, age 40 years

$\longrightarrow$ - moist mixed forest, age ca. 50-60 years

Vesijako Nature Park, no human interference

Lammi Evo Vahtervehmas forest reserve

Ruotsinpyhtää, Vahterpää, spruce stand

Oxalis-Myrtillus type

Ruotsinkylä Experimental Forest, mixed forest

- -, spruce stand in almost natural condition, no stumps

Tuusula, Katila, spruce stand

Lapinjärvi, old spruce stand

$\longrightarrow$-, mixed forest with abundant stumps

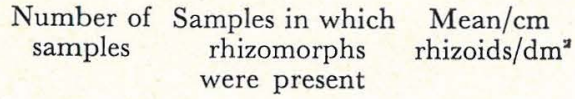

$\begin{array}{rrr}10 & 0 & 0 \\ 18 & 2 & 2.3 \gg \\ 7 & 2 & 6.1 \gg \\ 7 & 4 & 14.0 \gg \\ 2 & & \\ 2 & & 16.1 \gg \\ 12 & & 0.7 \gg \\ 23 & 2 & 0.3 \gg \\ 10 & 1 & 0.8 \gg \\ 10 & 1 & 20.4 \gg \\ & 2 & 1.2 \gg\end{array}$

\begin{tabular}{|c|c|c|}
\hline 5 & 2 & $2.3 \geqslant$ \\
\hline 6 & 1 & $5.9 \gg$ \\
\hline 5 & 2 & $9.7 》$ \\
\hline 6 & 1 & $0.9 \gg$ \\
\hline 6 & 2 & $1.2 》$ \\
\hline 4 & 4 & $121.2 》$ \\
\hline 5 & 5 & $10.4 \gg$ \\
\hline 6 & 6 & $56.6 \gg$ \\
\hline 7 & 2 & $6.6 \gg$ \\
\hline 4 & 1 & $5.9 \gg$ \\
\hline 7 & 7 & $21.5 》$ \\
\hline 0 & 8 & $22.0 \%$ \\
\hline 9 & 3 & $7.4 \gg$ \\
\hline 6 & 2 & $7.3 \gg$ \\
\hline 6 & 1 & $19.0 \%$ \\
\hline 6 & 1 & $4.1 \geqslant$ \\
\hline 6 & 1 & $6.9 *$ \\
\hline 4 & 4 & $53.0 \geqslant$ \\
\hline 5 & 5 & $34.1 \geqslant$ \\
\hline
\end{tabular}

taken more or less randomly with a spade, and in the laboratory all rhizomorphs were prepared and their length measured. The results are calculated as $\mathrm{cm}$ rhizomorphs in $1 \mathrm{dm}^{2}$ forest soil surface, down to the depth of the uppermost mineral soil, which is in dried forest types $5-4 \mathrm{~cm}$, in moister ones $5-10 \mathrm{~cm}$.

According to the present observations, main part of the rhizomorphs is restricted to the humus layer, only occasionally do they penetrate into the mineral soil. Although the values in Table 1 do not represent random samples, some features on the occurrence of rhizomorphs in forest soils can be seen. The lowest amount of rhizomorphs was found in dry pine heaths. Rhizomorphs were in general most abundant in moist thinned stands, especially if there were birch stumps present, but they occur also abundantly in perfectly primeval forests, as in Vesijako Nature Park, where no logging operations have taken place for at least 100 years. In the last-named area, Armillariella occurs also as a parasite in standing trees, as well as a saprophyte in dead logs.

The longest continuous rhizomorph was found in Punkaharju Experimental Forest in a Picea abies stand of Oxalis-Myrtillus type, and measured $560 \mathrm{~cm}$. Due to the presence of living tree roots, the excavation is usually very laborius, and so this value probably does not represent any maximum value. Hamada (1940, p. 196) recorded rhizomorphs over ten meters long in Japan.

Although rhizomorphs colonize stumps very rapidly after felling, basidiocarps can still be seen in rather old stumps, with an estimated age of up to 20-25 years. According to Griffin (1972) Armillariella elegans may survive saprophytically in tree remains for decades. 


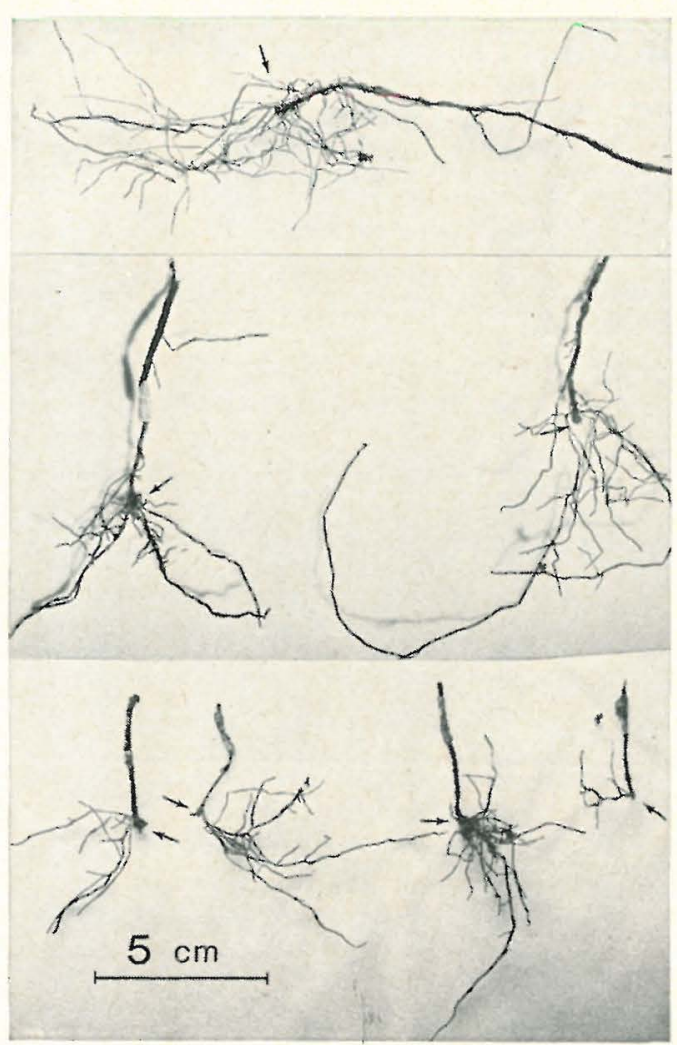

Fig. 8. Regeneration of living rhizomorphs in forest humus of Myrtillus type. The rhizomorphs were cut on July 30, 1968, marked, and taken away on May 30,1969 . Vigorous regeneration by thinner rhizomorphs took place at the cut point (arrow). Tuusula, Mätäkivi.

Regeneration of rhizomorphs. Attempts were made in the following way to study whether the rhizomorphs in the humus are living or dead.

1. Thicker rhizomorphs were located in the humus in natural situations, cut, the stump marked with a red plastic band, and then covered with humus and litter as naturally as possible. After several months, the rhizomorph was dug out, and regeneration was observed (Fig. 8). In all, about 50 rhizomorphs were observed in Ruotsinkylä Experimental forest, and most of them turned out to be living. In general, the growth rate of new rhizomorphs was at least several centimeters a month, if the moisture conditions were adequate.

2. Rhizomorphs were collected from humus and put in a bag made of nylon mesh, and put into the humus. Regeneration from the ends was often observed.

3. Rhizomorphs were also taken to the laboratory, put into quartz sand in petri dishes, moistened with distilled water and diluted ethanol solution $(0.05-5 \%$ in water). After some weeks, new growth of the rhizomorphs was seen.

On the basis of these experiments, it seems that the majority of rhizomorphs in the soil, especially those which look smooth and compact, are evidently living and capable of to producing new rhizomorphs when injured. If the nylon bags, which were put into the humus, contained older rhizomorphs, they became mouldy rather rapidly, evidently due to Trichoderma on the surface, and lost their compactness. Evidently the rhizomorphs remain dormant in the humus layer for extended periods, and on injury produce new branches.

\section{Growth of rhizomorphs in forest soils}

As in the previous laboratory experiment (p. 17) the rhizomorphs often grew out of the wood, the growth of rhizomorphs in the soil in natural habitats was studied in the following way.

$25 \mathrm{~cm}$ long and 5-10 $\mathrm{cm}$ thick freshly cut spruce wood pieces were inoculated in the middle of the piece, the wound covered with parafilm, the other end immersed in water and kept at $20^{\circ} \mathrm{C}$ for 2 months in the laboratory. The outgrowing rhizomorphs were cut off with a knife, and the wood pieces were placed in May 1971 into the humus layer of different habitats at approximately a depth of $10-15 \mathrm{~cm}$, and covered with humus and litter. All the pieces were found to have a vigorous mycelium of Armillariella under the bark. The wood pieces were collected in October 1971. Results in Fig. 9.

In general, the rhizomorphs grew out into the humus rather readily, even in relatively dry conditions, e.g. in a clearcut area on sandy soil. It is interesting to note that the rhizomorphs also grew in a pine bog, where the species is otherwise not found. In the previous summer (1970) similar experiments at the same place failed to support growth, the reason probably being due to the dry conditions of summer 1971. Evidently, sphagnum peat seems not to contain antibiotic substances known to occur in tropical areas 


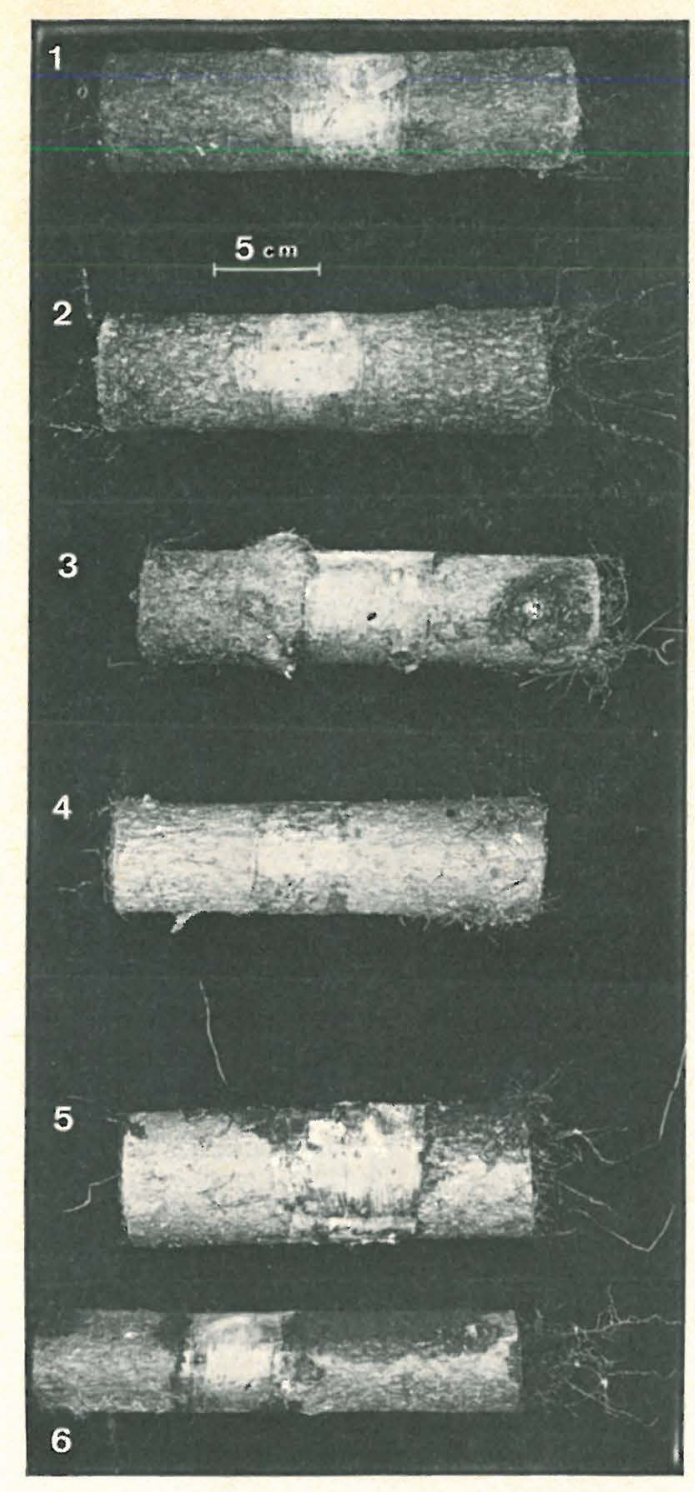

Fig. 9. Pieces of spruce wood, inoculated with a aseptic culture of Armillariella in March 1971, incubated in laboratory for two months, during which time the fungus had colonized the cambial layers. In May, all outgrowing rhizomorphs were cut, and the pieces were put into the humus layer of different biotopes in Ruotsinkylä Experimental Forest and photographed in October 1971. 1: Exposed clear-cut area on sand soil, 2: clear-cut area of Myrtillus type, 3 and 4: spruce stands of OxalisMyrtillus type, 5: pine bog, and 6: temporarily flooded soil near a brook.

(Swift 1968, Olembo 1972), which would prevent the growth of rhizomorphs in the soil. As a curiosity it may be mentioned that rhizomorphs grew well out of an inoculated wood piece lying partly submerged in water of a small brook (Fig. 9:6). According to Findlay (1951) and Ramsbottom (1952) rhizomorps may invade water-pipes.

Based on the above observations, it seems that the main limiting factor for rhizomorph growth in forest soils is the dryness, which in Finnish conditions is most pronounced in early summer and midsummer, when the optimum growth for rhizomorphs would prevail. Compared with the rapid advance of plate-like rhizomorphs in spruce bast, the rhizomorphs in the cases reported above seemed to grow much slower in humus.

\section{Colonization of wood by Armillariella in laboratory and in forest soils}

Attempts were made in the laboratory to simulate the colonization of fresh wood by Armillariella in the following way.

Fresh wood pieces, length $10-25 \mathrm{~cm}$, diameter $3-8 \mathrm{~cm}$, were surface sterilized with $\mathrm{H}_{2} \mathrm{O}_{2}(10 \%)$ or alcohol, a short cut was made with a sterile knife in the wood, and a piece of Armillariella mycelium on agar was forced into the phloem. The wound was covered with parafilm. The wood pieces were kept in the dark at $20^{\circ} \mathrm{C}$ with one end immersed in water. Usually the upper horizontal surface showed abundant mould growth, which, however, did not seem to interfere with the growth of Armillariella within the bast. Time 2 months.

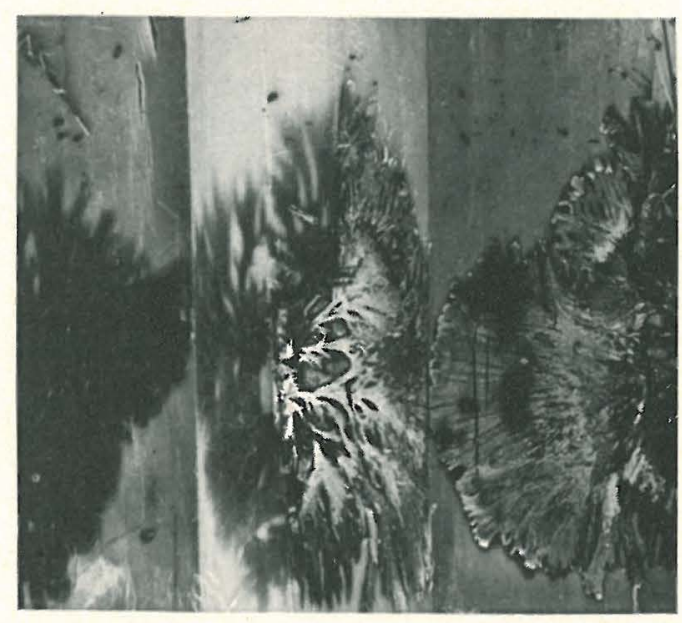

Fig. 10. Semiaseptic inoculation of Armillariella mellea in spruce bark. At right: rhizomorphs growing in phloem, at left: in outer bark layers. 


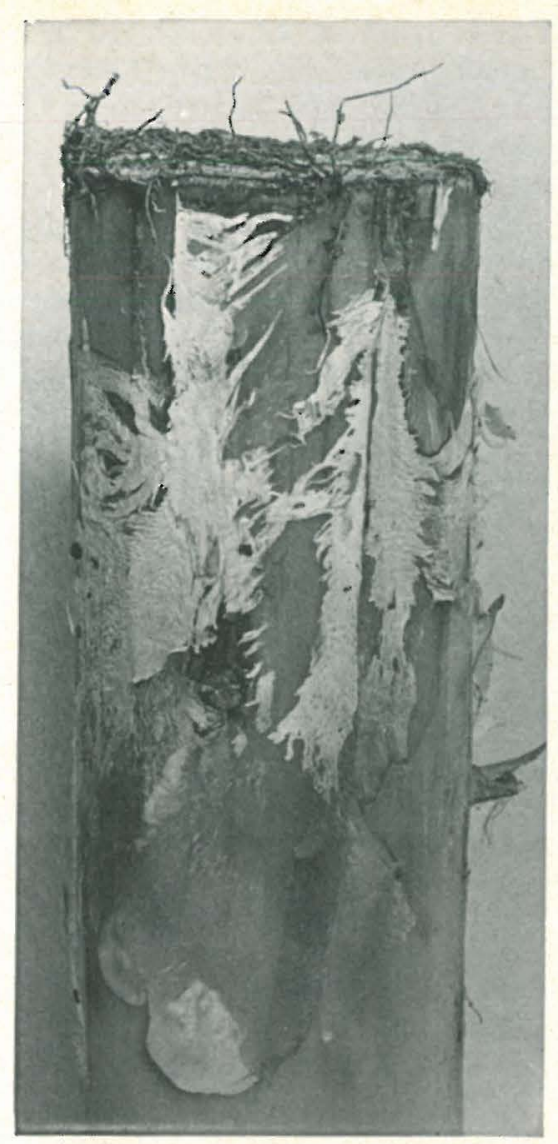

Fig. 11. Colonization of spruce wood in soil by Armillariella during 58 days in summer 1972 in Ruotsinkylä Exp. Forest, Katila. Penetration from ends and from branch stubs.

As a rule, it was very easy to inoculate wood of Picea abies. In two months, the whole of the phloem was colonized by platelike rhizomorphs, and from the lower end rhizomorphs often emerged into the water. Both phloem and cork cambium became colonized (Fig. 10). In the wood of Pinus silvestris, Larix sibirica, Abies balsamea and Betula verrucosa, the growth was slower and usually only reached about $10 \mathrm{~cm}$ from the point of inoculation. No rhizomorph growth was obtained in Acer platanoides, Sambucus racemosa, Populus tremula, Prunus padus, Alnus incana, Salix caprea, and Juniperus communis. These results agree fairly well with the observations made in nature on the host tree species.

Colonization of spruce rood in soil. On May 17, 1972, a small spruce tree was felled, cut into pieces $25 \mathrm{~cm}$ long, put into the humus layer of a spruce stand on clay soil, a Myrtillus type stand, and a spruce swamp at a depth of ca. $10 \mathrm{~cm}$ and then covered with humus and litter. In the beginning of July, rhizomorphs were seen to be growing on the surface of the pieces, and after 58 days, the subcortical type of rhizomorphs were growing in several of the spruce wood pieces, extending up to $10 \mathrm{~cm}$ from the site of infection, which was the cut surface or cut branch stump (Fig. 11); penetration through the uninjured bark was not observed.

This experiment indicates that the infection process by rhizomorphs can be very effective and occur in seasons when the possibilities of air-borne infections are small.

On July 27, 1972, freshly cut wood pieces of 8 tree species were put, as in the preceding experiment, into the forest humus of a spruce stand of Oxalis-Myrtillus type on clay soil, where rhizomorphs were known to occur abundantly. On October 19, after 84 days the wood pieces were investigated for the presence of rhizomorphs in the bark. In uninfected wood the bark was still green and evidently living. Spruce wood was colonized very easily, as well as pine and birch, Alnus incana and Populus more slowly, Sorbus and Juniperus not at all. It should be pointed that the wood pieces were merely put into the humus without any inoculation, and thus the rhizomorphs had to grow towards the wood, and find an injury site or pass from the cut ends into the cambium. Despite this initial delay, the colonization was very rapid, and during this time maximum growth of a single rhizomorph (based on the fan-like growth) of about $30 \mathrm{~cm}$ was measured. As the temperature in October was occasionally near $0^{\circ} \quad \mathrm{G}$ and for a long time around $5^{\circ} \mathrm{C}$, the growth rate must have been up to $5 \mathrm{~mm}$ a day in late summer. According to Sokolov (1971), rhizomorphs may grow up to $50 \mathrm{~cm}$ a month in summer near Leningrad.

Rhizomorphs were seen abundantly at places on the outer surface of the wood pieces, and without doubt the infection took place by rhizomorphs.

The summer of 1972 was exceptionally warm, and after midsummer the average daily temperature was often above $20^{\circ} \mathrm{C}$. In view of the slow growth of rhizomorphs at low temperatures, it seems that the high temperatures as well as the adequate moisture 
condition promoted the colonization of the wood by rhizomorphs.

In the summer of 1970, a similar experiment was carried out in Lapinjärvi Experimental Forest, where the wood pieces were placed vertically to a depth of $20-30 \mathrm{~cm}$ in a clay soil. A part of the pieces had been earlier kept in $5 \%$ ethanol, $5 \%$ acetic acid, acetone, and $5 \%$ glucose soluton. Colonization occurred in several cases during the growing season but only in untreated pieces. Several of the wood pieces were colonized by beetle (Hylobius, Pissodes sp.) larvae, which consumed the bast and probably made the spread of Armillariella rhizomorphs impossible. The insects colonized initially the more or less exposed parts, and those parts buried in the soil were more rapidly colonized by Armillariella.

The inhibition of the spread of Armillariella through the activity of insect larvae has been noted several times earlier (see SokoLov 1964). However, this depends on the special way in which the fungus spreads under the bark, and is different from e.g. blue stain fungi, which are in general promoted by the activity of insects in wood.

\section{Some ecologically important cultural characteristics of Armillariella mellea}

As the ecological investigations include both the study of external factors important for the organism in question, as well as the study of the corresponding physiological - ecological properties of the species in the laboratory, certain aspects of the physiology of the Finnish strains of Armillariella were investigated in connection with the present investigation.

Growth in relation to temperature. The relation of rhizomorph growth on temperature was studied by growing a strain in test tubes containing Hagem agar with $0.025 \%$ acetic acid as a stimulant, and measuring the downward daily growth at different temperatures. Fig. 12 indicates the results. It is remarkable that at low temperatures, around $+5-+10^{\circ} \mathrm{C}$, the growth rate is very slow, although these temperatures prevail for rather a long time in the deeper soil layers. It seems that the rhizomorphs are active only in relatively warm conditions and the fastest growth is expected in midsummer, if other factors are neglected. Sokolov (1971), in particular, emphasizes the short duration of the active period (ca. two months) in areas around Leningrad.

In regard to the radial growth of mycelium apart from the rhizomorphs, the optimum temperature for isolates made from pines was found to be between $25.0-27.5^{\circ} \mathrm{C}$ and for those from spruce wood between 22.5$25.0^{\circ} \mathrm{C}$.

Tolerance to high temperatures was studied by keeping $160 \times 16 \mathrm{~mm}$ test tubes in controlled water baths for various periods. As the rhizomorphs were situated within the agar, there was a time lapse in the effect of temperature. The rhizomorphs are killed rapidly

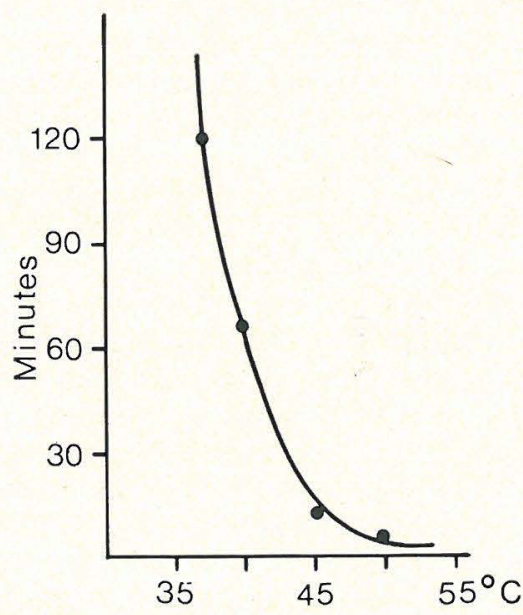

Fig. 12. Rhizomorph growth in relation to temperature in malt extract agar (left). At right: time necessary for killing the growing point of rhizomorphs in test tubes within agar, in relation to temperature. 
within a few minutes at temperatures above $45^{\circ}-50^{\circ}$ C. Usually the tip of the rhizomorph was killed first, and when the culture was kept at $25^{\circ} \mathrm{C}$, new branches emerged from the basal parts of the rhizomorphs.

In Finnish conditions, root temperatures exceeding the thermal tolerance of the rhizomorphs are never met with, and only in exposed situations may the temperature of the stem cambium rise to levels approaching the thermal limit.

\section{The effect of different substances on the production of rhizomorphs in aseptic culture}

The investigations of WEINHOLD (1963), Pentland (1965, see also Sortkjaer \& Allermann 1972) have established that ethanol has a strong stimulating effect on the formation of rhizomorphs. In connection with the present experiments, ethanol also exerted a definite stimulation, although there were strains which did not produce rhizomorphs in any ethanol concentrations. In addition, propanol (50-1000 ppm) and butanol had a slight stimulating action as well as acetic acid and acetates. Rhizomorphs were obtained fairly regularly, when $0.025 \%$ acetic acid was added to malt extract agar. As pointed out SortKJaer and Allerman (1972), the effect of acetate occurs in much more limited concentrations than that of ethanol.

In aseptic cultures, Armillariella rhizomorphs seem definitely to seek anaerobic conditions. If a glass plate is placed on an inoculum, the rhizomorphs are produced only when the mycelium has reached the air, and the rhizomorphs grow back under the glass (see also Fig. 13). According to investigations of JENNison et al. (1955) Armillariella also favours reducing media.

Ecologically, the stimulation by ethanol and acetate is interesting, because in the anaerobic conditions of forest soils, these substances are evidently produced by micro-organisms, which thus may promote infection by rhizomorphs. If the food base of rhizomorphs is in adequately aerated conditions, the tips of the rhizomorphs are to a considerable extent capable of growing under anaerobic conditions, in contrast to tree roots, which are quite sensitive to anaerobic conditions (GILL 1970). In addition, ethano! is produced in thicker logs in anaerobic conditions (MOEGK 1970, CADE et al. 1970).

However, indication of the orientation of rhizomorphs towards trees or agar containing ethanol was not succesful, when made in connection with the present investigation.

In addition, certain chemicals, like benzoic acid and trimethylbenzoic acid had a considerable effect on the growth and branching of rhizomorphs (Fig. 14).

\section{On the effects of carbon dioxide and oxygen on the gro'sth of Armillariella}

Within living and dead wood, the concentration of oxygen is lower and that of carbon dioxide higher than outside it, due to the dense structure of wood, which may play a considerable role in the ecology of woodinhabiting fungi (JENSEN 1967, HintikKa \& Korhonen 1970, SGHanel 1971). Recently, SMith \& Griffin (1971) have investigated the role of these substances in Armillariella elegans very comprehensively, and in particular, oxygen has been found to be ecologically important for controlling the growth and formation of rhizomorphs. Three experiments were made in this connection.

1. Armillariella was inoculated on $1 \%$ malt extract agar in 51 erlenmeyer flasks which were placed in a desiccator, known concentrations $\mathrm{CO}_{2}$ were then introduced with the

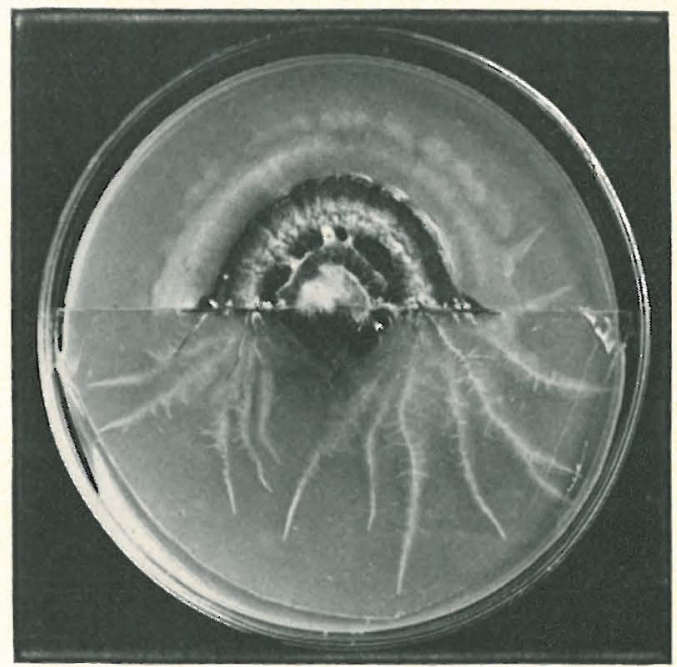

Fig. 13. Armillariella grown on $1 \%$ malt extract agar in a petri dish, the (lower) half of which is covered with a glass plate. Note the orientation of rhizomorphs into the less aerated parts of the medium. 


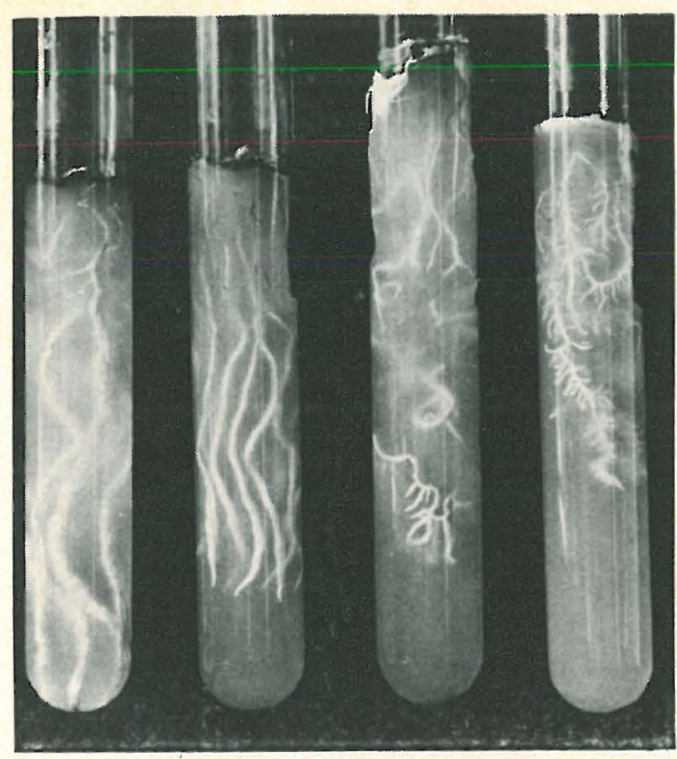

Fig. 14. The effect of some substances on the form of rhizomorphs. From the left: benzoic acid $0.025 \%$, cinnamic acid $0.05 \%$, acetic acid 0.025 $\%, 3,4,5$, trimethoxybenzoic acid $0.075 \%$ in $1 \%$ malt extract agar. Note broad rhizomorphs in benzoic acid and abundant branching in 3, 4, 5, - trimethylbenzoic acid.
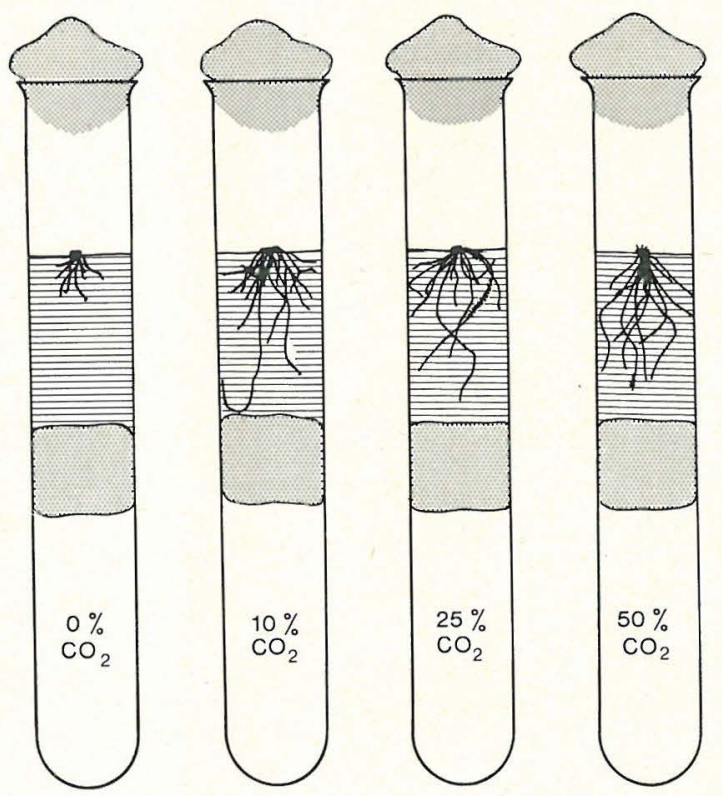

Fig. 15. Growth of rhizomorphs on $1 \%$ malt extract agar with different concentrations of carbon dioxide at the bottom of the tube. Note the stimulating effect of $\mathrm{CO}_{2}$. aid of a vacuum, and closed with rubber stoppers. Rhizomorphs developed only in low concentrations of $\mathrm{CO}_{2}, 0-1 \%$. In concentrations above $10 \%$, all crustose areas, formed at lower concentrations, were not developed and the aerial mycelium was pure white and abundant.

2. Armillariella was grown on $1 \%$ malt extract agar in test tubes, on the bottom of which was introduced different concentrations of carbon dioxide - air mixtures (Fig. 15). Carbon dioxside markedly stimulated the growth of rhizomorphs compared with the tubes in which the basal cavity was filled with ordinary air.

3. Armillariella was grown in test tubes on $1 \%$ malt agar, into which $0.05 \%$ methylene blue was added. The color of the methylene blue did not change around the rhizomorphs at the bottom of the test tubes. This type of experiment, which has earlier been made by a number of authors, indicates that the growing tip of rhizomorphs is evidently independent of the external supply of oxygen for its growth, and translocation of $\mathrm{O}_{2}$ takes place through the rhizomorphs from the agar surface. As the rhizomorphs are able to grow several centimetres into the air, the growth is also independent of the nutrients around the apex. In view of the rapid colonization of the bark by plate-like rhizomorphs, it is evident that this independence of external nutrient and oxygen supplies may be of great significance. As the rhizomorphs rely on an external oxygen supply situated farther away, they may be capable of colonizing irrespective of oxygen content, and probably also of toxic substances (see p. 23). Ecologically, carbon dioxide diffusing out from within tree roots and trunks may stimulate the growth of rhizomorphs. However, it remains to be determined, whether or not they actually orientate themselves according to this gas. In addition, a relatively high maximum concentration allows the growth of the mycelium within the trunks, although compared with other species which cause heart rot decay, the maximum concentration of Armillariella is considerably lower (JENSEN 1969, Hintikka \& KORHONEN 1970).

In addition, it should be noted that carbon dioxide effectively inhibits the luminescence of the mycelia. In the case of ordinary mycelia in the air, the luminescense is concentrated especially in the brown tufts in the crus- 
tose areas. Whitish aerial mycelium, which developed in $5 \%$ or higher concentrations, did not luminesce. Rhizomorphs did not give off light in either concentrations. Even a $1 \%$ $\mathrm{CO}_{2}$ concentration in the air markedly decreased the light emission which was not seen in $5 \%$ at all.

The nature of the inhibiting action of the bark of Sorbus aucuparia and Prunus padus

As the experiments reported on page 22 indicated that Armillariella did not grow under the living bark of freshly cut wood of Sorbus aucuparia and Prunus padus, the effect of the bark was studied in more detail. The bark of these trees is known to contain the cyanogenic glycosides, amygdalin and prunasin, which both produce hydrogen cyanide and benzaldehyde upon hydrolysis (EYJOLFSSON 1969, JONES 1972).

Experiments. A mycelium of Armillariella was grown on Hagem agar in a petri dish, placed above some crushed bark of Sorbus on the lid of the petri dish. The fungus did not grow, even when the respiration of the bark was inhibited by moistening it with 0.2 $\%$ sublimate solution. If a sterile extract prepared from the bark of Sorbus by Millipore filtration, which did not consume oxygen in Warburg apparatus, was kept in the same atmosphere as growing mycelia of Armillariella, complete inhibition was seen. Consequently, gaseous inhibiting substances occur in the bark.

If a paper containing $\mathrm{Na}_{2} \mathrm{CO}_{3}$ and picric acid was placed in the air phase, which on absorbing HCN turns red, the mycelia grew normally even though the crushed bark extract was in the same space. The paper turned reddish. This experiment suggests that HCN may be connected with the inhibition.

The tolerance of six strains of Armillariella to $\mathrm{HCN}$ was studied by inoculating the strains into petri dishes, placing then upside down in a desiccator, and then liberating measured amounts of HCN (formed from KCN by the action of sulfuric acid). The air within the desiccator was circulated with a magnetic stirrer (Hintikka 1970). $100 \mathrm{ppm}$ of HCN in the gas phase did not appreciably influence the growth, at a level of $316 \mathrm{ppm}$ the growth was about half of the control, and $1000 \mathrm{ppm}$ totally inhibited the growth. Benzaldehyde seemed to be less toxic than hydrogen cyanide.

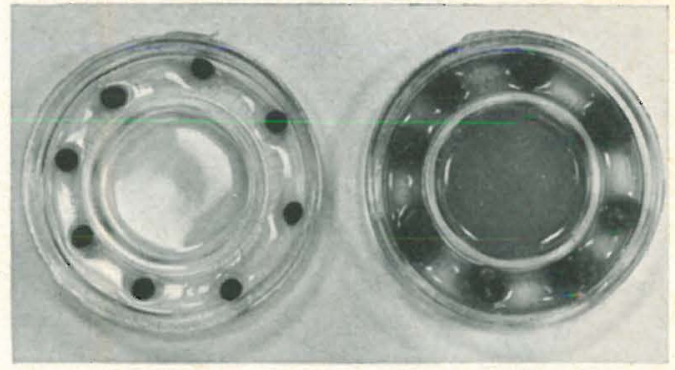

Fig. 16. Production of hydrogen cyanide from the bark of Sorbus aucuparia by Armillariella mellea. Left: Aseptically taken circles of Sorbus bark, right: inoculated with Armillariella. The picrate -sodium carbonate solution in the central well has changed dark due to production of hydrocyanic acid.

In addition, the mycelium of Armillariella may liberate HCN from the bark of Sorbus. Fig. 16 indicates an experiment, where disks of bark alone were placed in a Conway-dish, and inoculated with Armillariella. In the central well the alkaline picrate solution turned reddish only in the inoculated dishes, indicating that Armillariella actively liberates HCN from Sorbus bark.

The effect of terpenes. As inoculation experiments indicated (p. 14), the resin of conifers evidently forms an effective barrier for the penetration for Armillariella into living spruces and pines (see also Gribs 1968, Rishbeth 1972). One of the components of the resin are the monoterpenes, which form several per cents of the resin. It is possible that the gas phase at least in some places within the wood is saturated with monoterpenes among which alpha pinene is one of the most common ones. Compared with other fungi, Armillariella is considerably more sensitive than other heart-rot fungi, which are often able to grow even in saturated atmospheres of pinenes (Hintrkka 1970, VäISÄLÄ 1972). In connection with the present investigation, cultures of Armillariella were kept on $1 \%$ malt extract agar in desiccators saturated with alpha pinene (Fluka prakt., for method, see HintikKA 1970). By taking away cultures, it was found that the pinene killed the mycelia in $3-5$ days. Thus it seems that the mycelial phase in sensitive to resin terpenes, and not able to grow through saturated gas spaces. Also against phenolic compounds the species seems to be more sensitive than other parasitic wood-decomposing fungi (HINTIKKA 1971). 


\section{Discussion}

On the basis of the observations and experiments reported above, the rhizomorphs of Armillariella seem to play an important role in the colonization of wood by this fungus. This is, in fact, a commonly accepted view (Zycha 1970), which dates back to Hartig (1873). In the cases described in this paper, airborne infections seem to play a smaller role, although in the case of infections occurring in the fall, this fact must be taken into account, as it leads to a similar development of the subcortical rhizomorphs (RISHBETH 1970).

The amount of rhizomorphs in Finnish forest soils must be regarded as being surprisingly high, and in the biology of the humus layer they probably form an integrated part (cf. WENT 1973). It seems that they initiate from rotten wood and their future growth is dependent on this store of nutrients. Evidence of utilization of humus or leaves, apart from small twigs in the soil, through which rhizomorphs sometimes grow, was not observed. The hard surface layer of the rhizomorphs also seems to prevent the absorption of nutrients from the humus. In Nordic conditions, symbiotic occurrence with orchids (Hamada 1940) or with Monotropa (CAMpBELL 1971) seems to be unknown.

The basidiocarps of Armillariella often grow in stumps, which have an age since felling of about $15-20$ years. Evidently the species is continuously able to produce rhizomorphs, which in turn may remain dormant in the humus for longer times. The time is at least 20-30 years from the initial colonization of the wood but is probably much longer, although direct evidence is lacking. Evidently translocation is good in rhizomorphs, as the experiments on $\mathrm{O}_{2}$ (p. 21) indicate, and nutrients may also be translocated in the same way into the growing tip of the rhizomorphs from the wood colonized by the mycelium.

Based on the above experiments, the rhizomorphs, if externally hard and with an even surface, are by and large living in the forest humus. In this respect they are probably comparable to sclerotia, and should be regarded as resting stages. The physiology of this stage is not well known, although in regard to the infection of roots in the soil, this is a very critical one. What makes them remain dormant for a long time, and what conditions are needed to produce new branches, needs additional investigation. Evidently some kind of orientation of the rhizomorphs must take place in the humus layers, and the growing tips probably actively seek out tree roots or pieces of wood in the soil. When rhizomorphs were cut, it seemed that new regenerated branches started to grow without any special direction. On the other hand, rotten birch and spruce roots are often found, in which the rhizomorphs form a dense network on the surface, thus indicating that the bark had exerted a stimulus for rhizomorph orientation. Especially the bases of root branches are often densely crowded with rhizomorphs, but usually without infection. In the same way, when the rhizomorphs concentrate on the surface of wood lying on top of the soil (Fig. 17), it is probably due to some kind of stimulus and not as a result of undirectional growth. The following theoretical considerations can be made.

It is well established that both ethanol and acetate stimulate the formation of rhizomorphs in aseptic cultures. On the other hand, these substances occur in dead wood

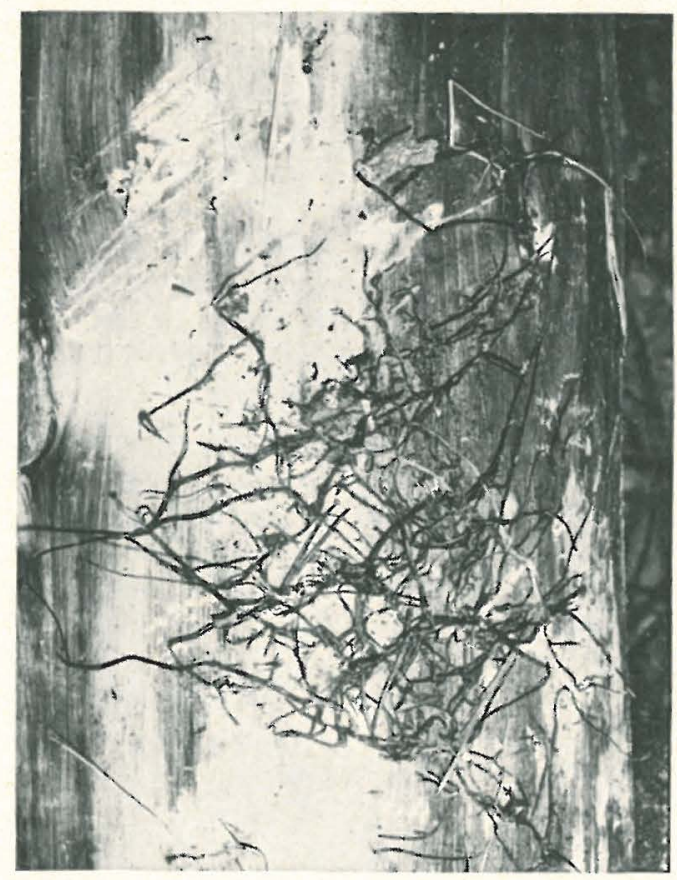

Fig. 17. Undersurface of a barked log, which has been lying on MT forest humus for one summer. All rhizomorphs developed during one summer. Ruotsinpyhtää, Kampuslandet, Sept. 1971. 
of at least some tree species in which ethanol is reported to function among others as an attractant to bark beetles (CADE et al. 1970). In addition, ethanol as well as acetate, may occur under anaerobic conditions in forest soils as a result of anaerobic fermentations. In these conditions, the roots of spruce, especially in warmer seasons, may be quite rapidly damaged as a result of anaerobic conditions (Veretennikov 1968, Gill 1970), which at least in theory may be suitable for colonization of rhizomorphs, as they are independent of the external oxygen supply at the growing tips.

An additional interesting feature may be the resistance of rhizomorphs to external toxins. As the surface layers of rhizomorphs are quite hard and impregnable, they may be able to tolerate higher toxin concentrations than the filamentous mycelium at least temporarily. As is well known, rhizomorphs can be surface sterilized with $\mathrm{H}_{2} \mathrm{O}_{2}$ without loosing their viability. This would suggest that infection by rhizomorphs may take place in wider environmental conditions than by spores.

The very rapid growth of rhizomorphs under the bark of spruce and pine, and some other conifers and hardwoods must be also especially emphasized. It seems that Armillariella is in particular well adapted to grow in the phloem by means of rhizomorphs, and the colonization of the xylem from the phloem seems to be much slower. In this regard, the species is probably insensitive to the antifungal substances in spruce bark studied by Alcubilla (1970), Algubilla \& Martin (1970), and Wenzel and Draz-Palagcio (1970).

In the infection process, the crucial question is, whether the rhizomorphs can penetrate through uninjured bark into the phloem and infect the root. Based on the above observations, rhizomorphs occur so abundantly in forest soils that if they were capable of penetrating through root bark, irrespective of the condition of the tree and nutrient supply of the rhizomorph, root infections should be much more abundant. On the other hand, in particular Thomas (1934) as well as Woeste (1956) have come to the conclusion that rhizomorphs are able to penetrate directly through the sound, healthy periderm of the host (see also GäUMANN 1946). In addition, SWIFT (1965) has observed loss of suberin from bark tissue rotted by Armillariella. Recently, with regard to Fomes annosus, BRAUN \& Lulev (1969) have indicated that this fungus can penetrate from an inoculated piece of wood pressed against the root through healthy bark into spruce roots. In general, it is supposed that good saprophytic nutrition is of essential importance for the aggressivity of the parasitic phase of Armillariella (ZYGHA 1970).

One point in connection with these experiments seems relevant. The tree roots, especially on clay or waterlogged soils are in continuous vertical movement during windy weather (HintikKa 1972), the magnitude of which may at a distance of 3-4 m from the stem be about $5 \mathrm{~cm}$, thus straining the roots considerably. In connection with these movements, small cracks can arise in the roots, especially when the roots are frozen, although direct evidence is so far lacking.

The penetration of phloem seems to require some degradation of the general physiology of the tree, and especially of the resin exudation. The main agent seems to be Fomes annosus -infection, which was present in most of the cases, where Armillariella had extensively colonized the bark of dying spruces (Fig. 18).

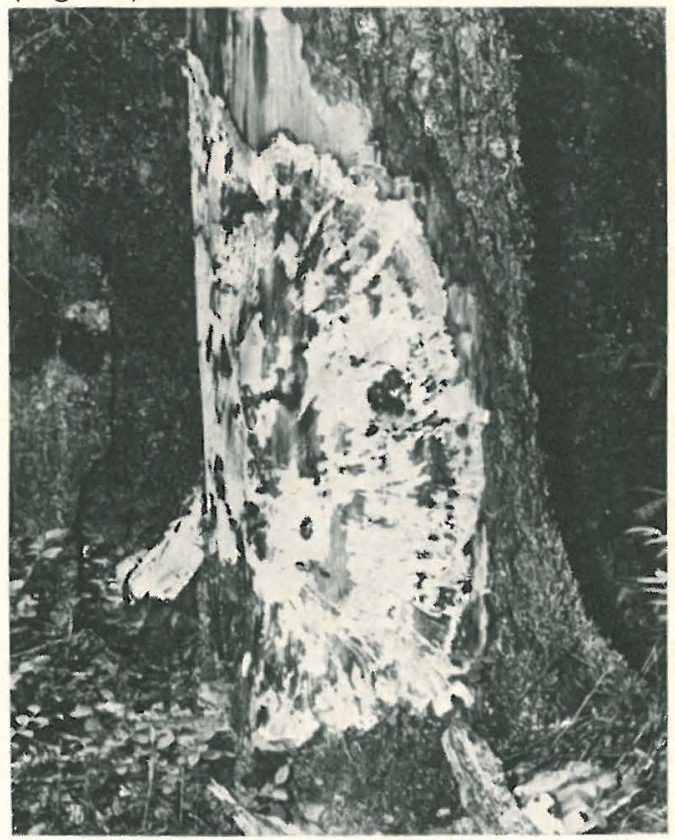

Fig. 18. Extensive subcortical mycelium at the base of a dying spruce, the heartwood of which was colonized by Fomes annosus. Bark removed for photography. Ruotsinpyhtää, August 1970. 
(ex Fr.) in the indigenous and exutic woodlands of Rhodesia. - Forestry 45, 57-86.

Thomas, H. E. 1934: Studies on Armillaria mellea (Vahl) Quél., infection parasitism, and host resistance. - J. Agr. Res. 48, 187-218.

Tuomıкoski, R. 1955: Sienet värikuvina. - Porvoo. $246 \mathrm{pp}$.

VäIs̈̈LÄ, L. 1972: Terpeenien vaikutuksesta puuta lahottavien lakkisienten kasvuun. - $\mathrm{Ma}$ nuscr. in Finnish Forest Res. Inst., Dept. Forest Protection. $61 \mathrm{pp}$.

WeInHold, A. R. 1963: Rhizomorph production by Armillaria mellea induced by ethanol and related compounds. - Science 142, 10651066.

WENT, F. W. 1973: Rhizomorphs in soil not connected with fungal fruiting bodies. - Am. J. Bot. 60, 103-110.

Wenzel, G. and Diaz-Palacio, M. P. 1970: Bezie- hungen zwischen dem Ernährungszustand der Fichte (Picea abies Karst.) und dem Pilzhemmstoffgehalt ihres Bastes. - Zeitschr. Pflanzenernähr. Bodenk. 127, 56-63.

Veretennikov, A. V. 1968: Fiziologicheskie osnovy ustoichivosti drevesnykh rastennii $\mathrm{k}$ vremennomy izbytku vlagi $\mathrm{v}$ pochve. - Moskva. $216 \mathrm{pp}$.

Woeste, U. 1956: Anatomische Untersuchungen über die Infektionswege einiger Wurzelpilze. - Phytopath. Zeitschr. 26, 225-272.

Yde-Andersen, A. 1959: Hallimasch als Ursache der Fichtenstockfäule. - Allg. Forstz. 14, $256-257$.

ZychA, H. 1970: Hallimasch. (Armillaria mellea Vahl ex Fr. Kumm.) als Kernfäule-Erreger an Fichte (Picea abies Karst.). - Forstwiss. Centr. 89, 129-135. 